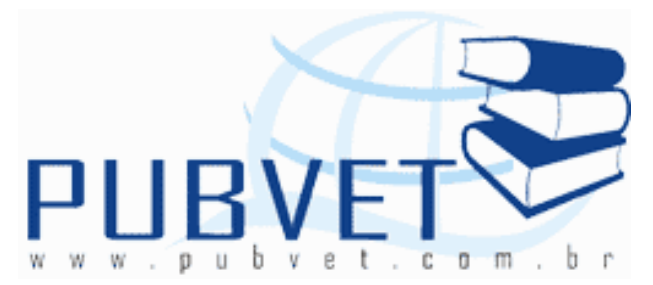

PUBVET, Publicações em Medicina Veterinária e Zootecnia.

\title{
Avaliação in vitro da erva de santa maria sobre Boophilus microplus
}

\footnotetext{
Pricilla Nascimento Pozzatti. ${ }^{1}$; Lenir Cardoso Porfírio ${ }^{2}$; Fernando Passon Casagrande ${ }^{3}$; Talita Pratti Valentim ${ }^{4}$; Bruna Bissi ${ }^{5}$; Breno Curty Barbosa ${ }^{6}$.

1,4,5,7 Profissional Médico Véterinário formado pela Universidade Federal do Espírito Santo.

${ }^{2}$ Professora Doutora do Departamento de Medicina Veterinária do Centro de Ciências Agrárias da Universidade Federal do Espírito Santo.

${ }^{3}$ Doutorando do Departamento de Clínica e Cirurgia da Escola de Veterinária da Universidade Federal de Minas Gerais.

${ }^{6}$ Granduando do curso de Medicina Veterinária da Universidade Federal do Espírito Santo.
}

\section{Resumo}

A erva de santa maria (Chenopodium ambrosioides L.) é uma das plantas usadas na fitoterapia humana, tendo sua origem na América tropical e subtropical, Antilhas e México, sendo muito abundante no Brasil. O Boophilus microplus conhecido como carrapato dos bovinos é um parasito de alta importância, produzindo perdas diretas e indiretas pela transmissão de doenças e alto custo de produtos para seu controle. Este trabalho avaliou o efeito de extratos fluidos $5 \%, 10 \%$, e $25 \%$ e glicólicos $10 \%, 20 \%, 30 \%$ e $50 \%$ de C. ambrosioides para controle do Boophilus microplus através do teste in 
POZZATTI, P.N. et al. Avaliação in vitro da erva de santa maria sobre Boophilus microplus. PUBVET, Londrina, V. 6, N. 5, Ed. 192, Art. 1293, 2012.

vitro. Este teste foi realizado com teleóginas para definição da concentração do produto através da eficácia reprodutiva. Foi observado que o produto que apresentou melhor resultado foi o extrato glicólico 50\% demonstrando 35,48\% de eficácia.

Palavras-chave: biocarrapaticidograma; carrapato; Chenopodium ambrosioides.

\section{In vitro evaluation of wormseed on Boophilus microplus}

\section{Abstract}

The wormseed (Chenopodium ambrosioides L.) is one of the plants used in herbal medicine human, having its origin in tropical and subtropical America, Caribbean and Mexico, being very abundant in Brazil. The Boophilus microplus known as tick of cattle is of high importance, producing direct and indirect losses for the transmission of diseases and high cost of products for your control. This study evaluated the effect of fluid extract $5 \%, 10 \%$ and $25 \%$ glycolic extract $10 \%, 20 \%, 30 \%$ and $50 \%$ of C. ambrosioides for control of Boophilus microplus by in vitro testing. This test was conducted with ticks to definition the concentration of the product through there productive efficiency. It was observed that the product had the best result was a $50 \%$ glycolic extract showing $35.48 \%$ effective.

Keywords: In vitro test; tick; Chenopodium ambrosioides.

\section{INTRODUÇÃO}

A fitoterapia é definida como o ramo da ciência médica que utiliza plantas, drogas vegetais e seus preparados para o tratamento de enfermidades (Sarti \& Carvalho, 2004). O Chenopodium ambrosioides L. (Ca) é uma das plantas comumente usadas como fitoterápicos, tendo sua origem na América tropical e subtropical, Antilhas e México. Muito abundante no Brasil, possui efeito antihelmíntico pela ação do princípio ativo ascaridol, que atua paralisando a 
POZZATTI, P.N. et al. Avaliação in vitro da erva de santa maria sobre Boophilus microplus. PUBVET, Londrina, V. 6, N. 5, Ed. 192, Art. 1293, 2012.

musculatura do parasito (Camargo, 1985). Apresenta também ação inseticida (Delobel \& Malonga, 1987) e repelente (Mazzonetto, 2002).

A erva de santa maria possui ainda como princípios ativos os glicosídios cianogenéticos, saponina (Projeto Guandu, 1995), cineol, cimeno, salicilato de metila, quenopodina, histamina, limaneno, glicol, ácidos butírico e salićlico (Albuquerque, 1989).

O Boophilus microplus é conhecido como carrapato dos bovinos, de alta importância, produzindo perdas diretas e indiretas pela transmissão de doenças e pelo alto custo no seu combate. Ainda hoje apresenta alta incidência e prevalência no Brasil e também em países desenvolvidos de clima tropical, como a Austrália, pela complexidade dos fatores envolvidos no seu combate e desconhecimento dos produtores das informações necessárias à adoção de práticas efetivas de controle (Rocha, 1996) que pode ser feito através de práticas de manejo e produtos químicos, mas que acarretam custos elevados, ocorrência de resíduos na carne e no leite, além do rápido desenvolvimento de resistência pelos carrapatos aos produtos utilizados (Fraga et al., 2003).

Diante das informações apresentadas, sobre o Chenopodium ambrosioides e visando o combate do Boophilus microplus foi avaliada a eficácia in vitro da erva de santa maria.

\section{MATERIAL E MÉTODOS}

Com base nos trabalhos de Drummond et al. (1973) citado por Campos Júnior \& Oliveira (2005) a metodologia utilizada para o teste in vitro foi o biocarrapaticidograma. Foram obtidas teleóginas de Boophilus microplus com tamanho igual ou superior a $4 \mathrm{~mm}$ provenientes dos animais controle da Empresa Brasileira de Pesquisa Agropecuária (EMBRAPA) Minas Gerais, os quais estavam sem uso de carrapaticidas. As teleóginas coletadas foram acondicionadas em vasilhames plásticos, identificados, limpos e aerados para o transporte de Belo Horizonte até o laboratório do Hospital Veterinário do Centro de Ciências Agrárias da Universidade Federal do Espírito Santo. 
POZZATTI, P.N. et al. Avaliação in vitro da erva de santa maria sobre Boophilus microplus. PUBVET, Londrina, V. 6, N. 5, Ed. 192, Art. 1293, 2012.

As teleóginas foram pesadas, lavadas com água corrente e peneira e secas em papel absorvente para evitar crescimento fúngico inesperado. Em seguida foram separadas em 9 (nove) grupos homogêneos com 10 (dez) carrapatos e em duplicata. A erva de santa maria foi utilizada em sete diferentes extrações e concentrações. Todos os carrapatos foram imersos nas diferentes soluções durante 2 minutos.

Os extratos glicólicos foram obtidos através do processo de maceração da folhas de erva de santa maria e colocado em contato com o líquido extrator. Os extratos fluidos foram obtidos também através das folhas, de forma que $1.000 \mathrm{~g}$ de extrato fluido possuíam o equivalente a $1.000 \mathrm{~g}$ da erva seca. Por não terem sofrido ação do calor, os princípios ativos dos extratos fluidos são exatamente os mesmos encontrados nas folhas da planta (ABIFISA, 2000). O líquido extrator utilizado foi o álcool de cereais em ambas as situações. A diluição dos extratos glicólicos e fluidos foi realizada em propilenoglicol e água respectivamente.

Os grupos e suas soluções foram os seguintes: Grupo A: extrato fluido $5 \%$ de (Ca). Grupo B: extrato fluido $10 \%$ de (Ca). Grupo C: extrato fluido $25 \%$ de (Ca). Grupo D: extrato glicólico 10\% de (Ca). Grupo E: extrato glicólico 20\% de (Ca). Grupo F: extrato glicólico 30\% de (Ca). Grupo G: extrato glicólico $50 \%$ de (Ca). Para todos os grupos havia dois grupos controle: um apenas com propilenoglicol e outro grupo com água.

Após a imersão na solução, as teleóginas foram secas em papel absorvente e acondicionadas em placas de Petri identificadas e mantidas a temperatura de $27^{\circ} \mathrm{C} \pm 1^{\circ} \mathrm{C}$ e umidade relativa do ar de $85 \% \pm 5 \%$. Foram registradas as principais variáveis: peso das posturas (do $15^{\circ}$ ao $18^{\circ}$ dia de postura), percentual de eclodibilidade (de 25 a 35 dias após a pesagem das massas de ovos), eficácia reprodutiva (ER) e eficácia do produto (EP). Após a pesagem e contagem, calculou-se as médias aritméticas das duplicatas de cada grupo segundo a fórmula de Drummond et al. (1973) citado por Campos Júnior \& Oliveira (2005). 
POZZATTI, P.N. et al. Avaliação in vitro da erva de santa maria sobre Boophilus microplus.

PUBVET, Londrina, V. 6, N. 5, Ed. 192, Art. 1293, 2012.

A eficácia reprodutiva foi calculada por:

$$
E R=\frac{\text { peso dos ovos } \times \% \text { eclosão } \times 20000 *}{\text { peso das teleóginas }}
$$

*A constante 20.000 significa o número estimado de ovos em $1 \mathrm{~g}$ de ovos de R. (Boophilus) microplus.

Para cálculo da eficácia reprodutiva as teleóginas foram agrupadas de forma homogênea sendo pesadas em balança de 3 dígitos BG 440 Gehaka.

A eficácia do produto foi calculada por:

$$
E P=\underline{E R} \text { grupo controle }-E R \text { grupo tratado } \times 100
$$

ER do grupo controle

\section{RESULTADOS E DISCUSSÃO}

Para o teste in vitro, as médias e os percentuais de eclodibilidade estão listados na Tabela 1.

Tabela 1. Pesagem e eclodibilidade dos ovos de Boophilus microplus de acordo com os produtos testados: extratos fluidos a 5, 10 e 25\%, extratos glicólicos a $10,20,30$ e $50 \%$, além dos controles água e propilenoglicol.

\begin{tabular}{lcc}
$\begin{array}{l}\text { Soluções de } \\
\begin{array}{l}\text { Chenopodium } \\
\text { ambrosioides }\end{array}\end{array}$ & $\begin{array}{l}\text { Pesagem da } \\
\text { Postura (g) }\end{array}$ & $\begin{array}{l}\text { Percentual de Eclodibilidade } \\
\mathbf{( \% )}\end{array}$ \\
\hline Extrato fluido 5\% & 0.726 & 98 \\
Extrato fluido 10\% & 0.7685 & 99 \\
Extrato fluido 25\% & 0.683 & 98 \\
Extrato glicólico 10\% & 0.594 & 96,5 \\
Extrato glicólico 20\% & 0.870 & 96 \\
Extrato glicólico 30\% & 0.9265 & 93,5 \\
Extrato glicólico 50\% & 0.579 & 98 \\
Controle água & 0.9825 & 100 \\
Controle propilenoglicol & 0.8795 & 100 \\
\hline
\end{tabular}


POZZATTI, P.N. et al. Avaliação in vitro da erva de santa maria sobre Boophilus microplus. PUBVET, Londrina, V. 6, N. 5, Ed. 192, Art. 1293, 2012.

Para cálculo da eficácia reprodutiva, as teleóginas foram agrupadas de forma homogênea com pesagem de $2 \mathrm{~g}$. Os cálculos da eficiência reprodutiva e eficácia produtos das diversas soluções são descritas na Tabela 2 e 3 respectivamente.

Tabela 2. Eficácia Reprodutiva nas soluções de extratos fluidos a 5, 10 e 25\%, extratos glicólicos a 10, 20, 30 e 50\%, além dos controles água e propilenoglicol.

\begin{tabular}{lc}
\hline \multicolumn{1}{c}{ Soluções } & $\begin{array}{c}\text { Eficácia } \\
\text { ReprodutivaA }\end{array}$ \\
\hline Água & 982500 \\
Propilenoglicol & 879500 \\
Extrato fluido $5 \%$ & 908460 \\
Extrato fluido $10 \%$ & 760815 \\
Extrato fluido $25 \%$ & 669340 \\
Extrato glicólico $10 \%$ & 573210 \\
Extrato glicólico 20\% & 835200 \\
Extrato glicólico 30\% & 866277 \\
Extrato glicólico 50\% & 567420 \\
\hline
\end{tabular}

${ }^{\mathrm{A}}$ Número de ovos estimados.

Tabela 3. Eficácia dos extratos fluidos a 5,10 e 25\%, extratos glicólicos a 10, 20, 30 e 50\% testados no biocarrapaticidograma em relação à água e ao propilenoglicol como controles.

\begin{tabular}{|c|c|c|}
\hline Solução de & Eficácia do Produto ${ }^{A}$ & \\
\hline erva-de-santa-maria & $\%$ & Eficácia do Produto ${ }^{\mathrm{B}} \%$ \\
\hline Extrato fluido $5 \%$ & 7,53 & 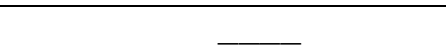 \\
\hline Extrato fluido $10 \%$ & 22,56 & ${ }^{-}$ \\
\hline Extrato fluido $25 \%$ & 31,87 & 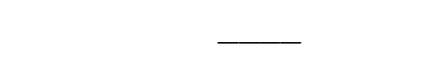 \\
\hline Extrato glicólico $10 \%$ & 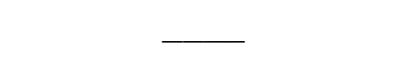 & 34,82 \\
\hline Extrato glicólico $20 \%$ & - & 5,03 \\
\hline Extrato glicólico $30 \%$ & - & 1,50 \\
\hline Extrato glicólico 50\% & 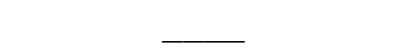 & 35,48 \\
\hline
\end{tabular}


POZZATTI, P.N. et al. Avaliação in vitro da erva de santa maria sobre Boophilus microplus.

PUBVET, Londrina, V. 6, N. 5, Ed. 192, Art. 1293, 2012.

No teste in vitro foi encontrado um percentual de eclodibilidade de Boophilus microplus variando de 93,5 a 99\% sem considerar os controles que foram de $100 \%$, resultados semelhantes aos encontrados por Bittencourt (1990) e Gloria et al. (1993).

Para que um produto natural seja considerado eficaz no controle do carrapato, deve possuir resultados como os de Costa et al. (2008) que apresentaram eficácia de $96 \%$ com extratos brutos hidroalcoólicos desidratados (EBHAD) de eucalipto a 10\%, de Silva et al. (2000) que obtiveram resultados do tratamento com clorfenvinfós apresentando eficácia de $100 \%$ e Marques et al. (1995) que encontraram eficácia de $100 \%$ no tratamento com ivermectina.

No presente trabalho, o produto que apresentou melhor eficácia foi o extrato glicólico 50\% com eficácia de 35,48\%. Diferente dos resultados obtidos por Chagas (2002) que obteve eficácia de $100 \%$ com extratos de Eucalyptus citriodora e Costa et al. (2008) encontraram eficácia de $96 \%$ usando extratos brutos hidroalcoólicos desidratados (EBHAD) eucalipto a 10\%, mas confirmando os resultados de Silva \& Santos (2008) que com a concentração de $90 \%$ de extrato botânico aquoso de C. ambrosioides obtiveram eficácia de $47,7 \%$.

\section{CONCLUSÃO}

A erva de santa maria nas diversas extrações e concentrações de extratos fluídos $5 \%$ e $10 \%$ e $25 \%$ extratos glicólicos $10 \%, 20 \%$, 30\% e 50\% não apresentaram eficácia superior a 35,48\%, sendo esta eficácia pertencente ao extrato glicólico a $50 \%$.

\section{REFERÊNCIAS BIBLIOGRÁFICAS}

ABIFISA (2000) Associação Brasileira das Empresas do Setor Fitoterápico, Suplemento Alimentar e de Promoção a Saúde. Disponível em: www.abifisa.org.br/saibamais_conceitos.asp. Acesso em: 08 de julho de 2011. Albuquerque JM (1989) Plantas medicinais de uso popular. Brasília, ABEAS. 100p. 
Bittencourt AJ (1990) Comportamento do Boophilus microplus (Canestrini, 1887) (Acari) em infestações artificiais e naturais em diferentes hospedeiros. Arquivos da Universidade Federal Rural do Rio de Janeiro, 13:173-182.

Camargo MTLA (1985) Medicina popular. São Paulo, Almed. 130p.

Campos Júnior DA \& Oliveira PR (2005) Avaliação in vitro da eficácia de acaricidas sobre Boophilus microplus (Canestrini, 1887) (Acari: Ixodidae) de bovinos no município de Ilhéus, Bahia, Brasil. Ciência Rural, 35:1386-1392.

Chagas ACS (2002) Efeito acaricida de óleos essenciais e concentrados emulsionáveis de Eucalyptus spp em Boophilus microp/us. Brazilian Journal of Veterinary Research and Animal Science, 39:247-253.

Costa FB, Vasconcelos PSS, Silva AMM, Brandão VM, Silva IA, Teixeira WC, Guerra RMSN \& Santos ACG (2008) Eficácia de fitoterápicos em fêmeas ingurgitadas de Boophilus microplus, provenientes da mesorregião oeste do maranhão, Brasil. Revista Brasileira de Parasitologia Veterinária, 17:83-86.

Delobel A \& Malonga P (1987) Insecticidal properties of six plant materials against Caryedon serratus (Olivier) (Coleoptera: Bruchidae). Journal of Stored Products Research, 23:173-176.

Fraga AB, Alencar MM, Figueiredo LA, Razook AG \& Cyrillo JNSG (2003) Análise de fatores genéticos e ambientais que afetam a infestação de fêmeas bovinas da raça Caracu por carrapatos (Boophilus microp/us). Revista Brasileira de Zootecnia, 32:1578-1586.

Gloria MA, Faccini JLH, Daemon E \& Grissi L (1993) Biologia comparativa da fase não parasitária de estirpes de Boophilus microplus (Canestrini, 1887) resistente e sensível a carrapaticidas em condições de laboratório. Revista Brasileira de Parasitologia Veterinária, 2:79-84.

Marques AO, Arantes GJ \& Silva CR (1995) Avaliação da eficácia da ivermectina a 1\% (solução injetável), no tratamento de bovinos naturalmente infestados pelo carrapato Boophilus microplus (canestrini, 1887) (acari: ixodide) e mantidos em pastagem. Revista Brasileira de Parasitologia Veterinária, 4:117-119,

Mazzonetto F (2002) Efeito de genótipos de feijoeiro e de pós de origem vegetal sobre Zabrotes subfasciatus (Boh.) e Acanthoscelides obtectus (Say) (Col.: Bruchidae). Tese de Doutorado. Escola Superior de Agricultura "Luiz de Queiroz". Piracicaba, 134p.

Projeto Guandu (1995) Terra, água e chá. ITA. 311p.

Rocha CMBM (2005) Caracterização da percepção dos produtores de leite do município de Divinópolis/MG sobre a importância do carrapato Boophilus microp/us e fatores determinantes das formas de combate utilizadas. Dissertação de Mestrado. Escola de Veterinária, Minas Gerais, 1996p.

Sarti SJ \& Carvalho JCT (2004) Fitoterápicos e anti-inflamatórios: aspectos químicos, farmacológicos e aplicações terapêuticas. In: Carvalho JCT (Eds.) Fitoterapia e fitoterápicos. São Paulo, Tecmed. p.13-38.

Silva EG \& Santos ACG (2008) Avaliação de extratos botânicos aquosos in vitro sobre larvas de Boophilus microplus (Canestrini, 1887) (acari: Ixodidae) em diferentes concentrações sob condições de laboratório. In: XX Semana de Iniciação Científica, São Luís. Anais. 
Silva MCL, Sobrinho RN \& Linhares GFC (2000) Avaliação in vitro da eficácia do clorfenvinfós e da cialotrina sobre o Boophilus microplus, colhidos em bovinos da bacia leiteira da microrregião de Goiânia-Goiás. Ciência Animal Brasileira, 1:143-148. 